Analytical Methods in Environmental Chemistry Journal Vol 2 (2019) 73-86

Research Article, Issue 1
Analytical Methods in Environmental Chemistry Journal
AMECJ

\title{
A new analytical method based on bismuth oxide-fullerene nanoparticles and photocatalytic oxidation technique for toluene removal from workplace air
}

\author{
Cobra Jamshidzadeh a and Hamid Shirkhanloo ${ }^{\text {b,* }}$
}

a Occupational Health Engineering Department, School of Public Health, Kerman University of Medical Sciences, Kerman, Iran

${ }^{b}$ Research Institute of Petroleum Industry, West Entrance Blvd., Olympic Village, P.O. Box: 14857-33111, Tehran, Fax: +98 2148251

\section{A R T I C L E I N F O:}

Received 28 Nov 2019

Revised form 4 Feb 2019

Accepted 5 Mar 2019

Available online 29 Mar 2019

\section{Keywords:}

Toluene

Air removal

Bismuth oxide nanoparticles

bulky fullerene nanoparticles

UV-photocatalytic

Solid gas phase extraction

\begin{abstract}
A B S T R A C T
A new sorbent based on mixture of bismuth oxide-fullerene nanoparticles $\left(\mathrm{Bi}_{2} \mathrm{O}_{3}-\mathrm{NF}\right)$ was used for degradation/removal of toluene from workplace and artificial air by UV-photocatalytic oxidation method (UV-PCOM). By set up of pilot, standard gas of toluene was generated with difference concentrations, and then was passed through UV lamp-glass quartz cell accessory(UV-GQC) by SKC pump at optimized flow rate. Following the UV irradiation, the electrons and holes can undergo redox reactions with toluene on the $\mathrm{Bi}_{2} \mathrm{O}_{3}$ surface that lead to the formation of toluene intermediates and toluene. Toluene and intermediates was physically and radically absorbed on the $200 \mathrm{mg}$ of NF at room temperature and then, desorbed from it at 185 ${ }^{\circ} \mathrm{C}$ before determined by GC/FID. In optimized conditions, the adsorption capacity and removal efficiency of NF were obtained $212 \mathrm{mg} \mathrm{g}^{-1}$ and more than $95 \%$, respectively. The chemically absorption mechanism of toluene on NF was mainly obtained due to radically group of $\mathrm{NF}\left(\mathrm{OH}^{\circ}\right.$, $\left.\mathrm{CO}^{\circ}\right)$ with methyl of toluene $\left(\mathrm{CH}_{2}^{\circ}\right)$ and physically adsorption depend on characterization of NF. In addition the flow rate and temperature had highly impact on NF for removal efficiency and absorption capacity of toluene from workplace and artificial air.
\end{abstract}

\section{Introduction}

The most Pollutants such as volatile organic compounds (VOCs, BTEX)and semi-volatile compounds (SVOCs, Di-nitrotoluene) release to air and environment by various industrial processes and human activity such as petrochemical facilities, motor vehicles, metal processing/finishing industries, gas stations, and energy sectors. Transport-derived emissions of volatile organic compounds (VOCs) have decreased owing to

\footnotetext{
* Corresponding Authors: Hamid Shirkhanloo Email: hamidshirkhanloo@gmail.com

DOI: https://doi.org/10.24200/amecj.v2.i01.55
}

stricter controls on air pollution. The high fraction of volatile chemical products (VCP) emissions is consistent with observed urban outdoor and indoor air. VCP contribute fully one-half of emitted VOCs in industrialized cities. Based on previous study, the toluene concentration was the most predominant among all the targeted compounds in air. So, removal of toluene from air is very important [1-5]. These compounds (VOCs) are associated with allergies and adverse respiratory effects [6] and some of them have been classified as carcinogenic to humans (benzene, formaldehyde) by the International Agency for Research on cancer[7] . A complex 
combination of physicochemical and biological phenomena takes place to finally convert pollutants into innocuous compounds (mostly $\mathrm{CO}_{2}, \mathrm{H}_{2} \mathrm{O}$ and biomass)[8]. The accumulation of VOCs is the greatest problem in air atmospheric pollutions with cars or industrial activity. The BTEX pollutants (benzene, toluene, ethylbenzene and xylenes) generated in air by gasoline combustion in car engines and caused a risk to human health[9]. The BTEX have a carcinogens effect in humans. They readily volatilized and distributed over large regions of air and have important role in photochemical oxidants and organic aerosols[10]. Among various types of VOCs, toluene is one of the most commonly used substances in industry and commerce as a solvent in paints, siliconesealants, many chemical reactants, rubber, printing ink, adhesives (glues), lacquers, leather tanners, and disinfectants[11, 12]. Most of VOCs are regarded as toxic compounds for human beings and the environment. symptoms associated with exposure to VOCs include eye irritation, nose and throat discomfort, headache, allergic skin reaction, nausea, fatigue, or dizziness, nervous system effects, liver toxicity, cancer[13, 14]. If inhaled or contacted, toluene can cause dermatitis (dry, red, cracked skin) and damage the nervous system and kidneys[12, 15]. The 8-h time-weighted average (TWA) for occupational exposure to toluenein accordance with ACGIH, OSHA, NIOSH methods is respectively 50, 200 and $100 \mathrm{ppm}$. Therefore, toluene emission control has become more stringent. Growing concerns on exposure to toxic air pollutants has led to intensive search for the best available technology for remediation of air pollutants[16, 17]. A number of physical, chemical and biological technologies such as membrane separation[14] 'adsorption[18], catalytic oxidation[19] and advanced oxidation[20] have been developed to remove VOCs successfully. The control of toluene emission is often accomplished by catalytic oxidation or adsorption. The adsorption process is widely used as a simple and effective operation[21]. Adsorption of VOCs by activated carbon (AC) has proven to besustainable, environmentally friendly, economical and efficient which makes it the most commonly used technique[22]. Toluene removal by adsorption is the traditional method for cleaning air contaminants [23-25]. However, the use of adsorbents just transfers pollutants from the gaseous phase to the solid phase and causes a disposal and regeneration problem[15]. Many studies have been done to remove toluene using carbon adsorbent such as activated carbon fibers (ACFs)[22], $\mathrm{NaOCl}$ oxidized carbon nanotubes[26], Zeolite[15],Nanographene modified by ionic liquid[27] . Buckminsterfullerene(C60) a hydrophobic molecule comprise a class of nanomaterials that are made of a newly discovered allotrope of carbon and composed of 60 carbon atoms arranged in a hollow spheres, ellipsoids, or tubes spherical shape, has gained wide application in many industries, including biomedical technology, electronics, optics, and cosmetics[28-30]. In recent years, advanced oxidation processes have been considered as a way to pollute organic pollutants. These methods are based on the production of highly active species such as hydroxyl radicals $\left(\mathrm{OH}^{0}\right)$ that can oxidize a wide range of organic pollutants. Among the advanced oxidation processes, heterogeneous photocatalytic are used as a successful method for the analysis of organic pollutants[31-33]. Degradation of volatile organic compounds such as, o-xylene, n-hexane, n-octane, n-decane, methylcyclohexane and 2,2,4-trimethylpentane in the gas phase by heterogeneous photocatalysis with titanium dioxide/ultraviolet light was achived at 52$62^{\circ} \mathrm{C}$. in this way, devices based on heterogeneous photocatalysis do not need flame for VOC oxidation, this will allow it to be installed safely even in areas vulnerable to fire and explosion[34, 35]. In this study, the UV-PCOM based on $\mathrm{Bi}_{2} \mathrm{O}_{3}$-NFwas used for efficient removal of toluene from air. The $\mathrm{Bi}_{2} \mathrm{O}_{3} /$ UV irradiation increased the removal efficiency of toluene from air by chemically adsorption of NF. Experimental parameters such as concentration, UV irradiation, temperature, the value of $\mathrm{Bi}_{2} \mathrm{O}_{3}$ $\mathrm{NF}$, flow rate, contact time, desorption, absorption, and repeatability were studied and optimized. 
The performance of the proposed method was evaluated.

\section{Experimental}

\section{1. Instrumental:}

Gas chromatography (GC) was used for determination of toluene in air (Agilent, Netherland). The FID detector was selected for toluene analysis in air/gas. The polyethylene tubes (PET) are simple devices that introduce a pure air stream from electro air cleaner (EAC, Canada, model HEPA 600M) into bags. Adjusted valves are used to control of gas flow rate from Germany. For sampling, the air bags, septum port and air sampling apparatus were used. GC equipped with a split/splitless injector, FID, and a column coated with cross-linked polydimethylsiloxane gum (50 $\mathrm{m} \times 0.2 \mathrm{~mm}$ id.). For determining of toluene with $\mathrm{GC}$, The temperature of injector and detector was adjusted to $200^{\circ} \mathrm{C}$ and $2700^{\circ} \mathrm{C}$, respectively. The temperature of oven was tuned from $0 .{ }^{\circ} \mathrm{C}$ to $r 40^{\circ} \mathrm{C}$ which was held for $10 \mathrm{~min}$. Hydrogen as the carrier gas was used at a flow rate of $1.0 \mathrm{~mL} \mathrm{~min}^{-1}$ with split ratio of $1: 100$. The different volumes of glass vials (10-200 mL, Aldrich, Germany) with air tight cap (PTFE) were used in batch or static system. The polyethylene tubes and bags were used as a transport and storage of air in static/ dynamic system. TGS 2180 (China) and Dräger Pac 3500 (Lübeck, Germany) detectors were used for continuous measurement of $\mathrm{H}_{2} \mathrm{O}$ vapor and $\mathrm{O}_{2}$ concentrations in gas fluid, respectively. The TGS detector has high sensitivity to water vapor and its conductivity depends on absolute humidity $\left(0.7 \sim 150 \mathrm{gm}^{-3}\right)$. Preheat of tubes and bags caused to capture water droplets. The toluene evaporated from chamber accessory, mixed with purified air and introduced to bags. For validation of methodology, the concentration of toluene in polyethylene bags was determined by GC-MS before and after passed through $\mathrm{Bi}_{2} \mathrm{O}_{3}-\mathrm{NF}$. The quartz glass tube (QGT, $10 \mathrm{~cm}$ ) as a column sorbent was used for $\mathrm{Bi}_{2} \mathrm{O}_{3}-$ NF. In this study, QGT with $0.4 \mathrm{~cm}$ diameter and $10 \mathrm{~cm}$ length was filled with $200 \mathrm{mg}$ of $\mathrm{Bi}_{2} \mathrm{O}_{3}$ NF. The gas tight syringes (SGE) were used for sampling of toluene and injection to GC. In this study, toluene generation system, QGT, PET, bags, electric power supply accessory $\left(50-280 \mathrm{~V}_{\mathrm{AC}}, 10 \mathrm{~A}\right.$, $20-800^{\circ} \mathrm{C}$, Italy), pneumatic valves (Germany) and Ar gas were used for evaluation of toluene removal from air. The accuracy of results was achieved by injecting a standard concentration of toluene in the chamber accessory before determined by GC-FID/ GC-MS.

\subsection{Reagents and solutions}

All reagents with high purity and analytical grade were purchased from Merck and sigma Aldrich (Darmstadt, Germany). All aqueous solutions were prepared in ultra-pure deionized water $(\mathrm{R} \geq 18 \mathrm{M} \Omega$ $\mathrm{cm}^{-1}$ ) from Milli-Q plus water purification system (Millipore, Bedford, MA, USA). The analytical grade of toluene solution was purchased from Sigma Aldrich, Germany (CAS N: 108-88-3, 99.8\%). For calibration of toluene, the approximate concentrations of toluene in methanol were prepared by $0.1,0.2,0.3,0.4,0.5,1.0,2.0$, and $5.0 \%(\mathrm{v} / \mathrm{v})$. The analytical grades of other reagents such as, $\mathrm{HNO}_{3}, \mathrm{HCl}$, methanol, ethanol and acetone were prepared from Merck (Germany). Bismuth nitrate $\left(\mathrm{Bi}\left(\mathrm{NO}_{3}\right) .5 \mathrm{H}_{2} \mathrm{O}\right)$, sorbitol and distilled water used for the preparation of $\mathrm{Bi}_{2} \mathrm{O}_{3}$ nanoparticles. Bismuth nitrate (CAS N: 383074 ) and sorbitol (CAS N: 5070-4) were purchased from Sigma Aldrich. The solutions were freshly prepared and stored just in a fridge $\left(4^{\circ} \mathrm{C}\right)$ to prevent decomposition. All the laboratory glassware and plastics were cleaned by soaking in nitric acid $(10 \%, \mathrm{v} / \mathrm{v})$ for at least $24 \mathrm{~h}$ and then rinsed with deionized water before use.

\subsection{Synthesis bismuth oxide and fullerene nanoparticles}

Bismuth oxide nanoparticles (BONPs) were prepared by special solid dispersion evaporation technique (SDAT) with carrier solutions such as sorbitol and flame sprays pyrolysis technique (FSPT) by organodimethicone (ODIM). By SDAT Synthesis, $5 \mathrm{~g}$ of solid bismuth nitrate [Bi $\left.\left(\mathrm{NO}_{3}\right) .5 \mathrm{H}_{2} \mathrm{O}\right]$ dissolve in carrier solutions $(5 \mathrm{ml})$ and stirred for $20 \mathrm{~min}$ at room temperature followed 
by sonication at $25^{\circ} \mathrm{C}$ in an ultrasonic bath $(40 \mathrm{kHz}$ and $100 \mathrm{~W}$ ). The mixture was diluted with $10 \mathrm{~mL}$ of distilled water and put on heater magnet stirrer plate for $30 \mathrm{~min}$. The $\mathrm{pH}$ of sample solution was optimized up to 7 and no precipitation was occurred during processes. The oven provided programmable heating up to $90-110{ }^{\circ} \mathrm{C}$ for $50 \mathrm{~min}$. Then dark brown sediment was formed after the evaporation of water. After 1 hour yellow sediment was formed in $550-600^{\circ} \mathrm{C}$ and nano particles is decomposed at $800-1200{ }^{\circ} \mathrm{C}$. In order to obtain pure BONPs and remove the metal nanocatalysts, the product was stirred in $18 \% \mathrm{HCl}$ solution for about $16 \mathrm{~h}$ at an ambient temperature. Then, the sample was washed repeatedly $(10 \mathrm{~N})$ with deionized water until the solution became neutral. The treated product was finally dried in oven at $100^{\circ} \mathrm{C}$. So, bismuth nitrate, sorbitol and distilled water used for the preparation of $\mathrm{Bi}_{2} \mathrm{O}_{3}$ nanoparticles medical grade by proposed procedure. For synthesis of fullerene (NF), fullerene soot (FS) was purchased from Sigma-Aldrich and pure fullerene (NF) was achieved with activated carbonand silica gel (TEM size: 30-100 nm) [36]. The pure fullerene (C60) from fullerene soot (FS) was done by two methods. By first procedure, a Soxhlet extractor with toluene was used for separation of light and heavy fullerenes (Fig. 1). The electric arc was used for producing of FS with low purity up to $7 \%$. The second way was obtained by column chromatography with stationary phase and mobile phase of activated carbon/ silica gel and chlorobenzene, respectively.

\subsection{Characterization}

The morphology of the mesh sorbent $\mathrm{Bi}_{2} \mathrm{O}_{3}$ and NF was examined using scanning electron microscopy (SEM, Phillips, PW3710, Netherland) and transmission electron microscopy (TEM, CM30, Philips, Netherland). The nanoparticle powder of $\mathrm{Bi}_{2} \mathrm{O}_{3}$ is dissolved in water or ethanol with ultrasonic bath and after drying, was prepared for TEM in scale of 50-100 $\mathrm{nm}$. The elemental composition of the samples was tested by energy dispersive X-ray microanalyser (EDX, QuanTax 200, Rontec, Germany) which was attached to SEM. X-ray diffraction (XRD) patterns for $\mathrm{Bi}_{2} \mathrm{O}_{3}$ nanoparticles were recorded by a GBC MMA diffractometer

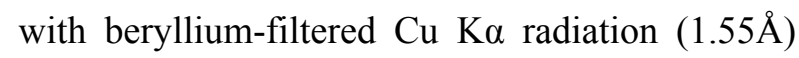
operating at $35.3 \mathrm{kV}$ and $30 \mathrm{~mA}$. FT-IR 8400 (Kyoto, Japan); UV-vis spectrophotometers Scinco S-2100 (SCINCO, Twin Lakes, WI, USA), NMR Jeol 90 MHz (JEOL Ltd., Tokyo, Japan), and rotary evaporator (Heidolph Laborota 4000, Schwabach, Germany) were used for nanofullerene (NF) characterization.

\subsection{Removal Procedure}

The concentration of toluene vapor in pure air was
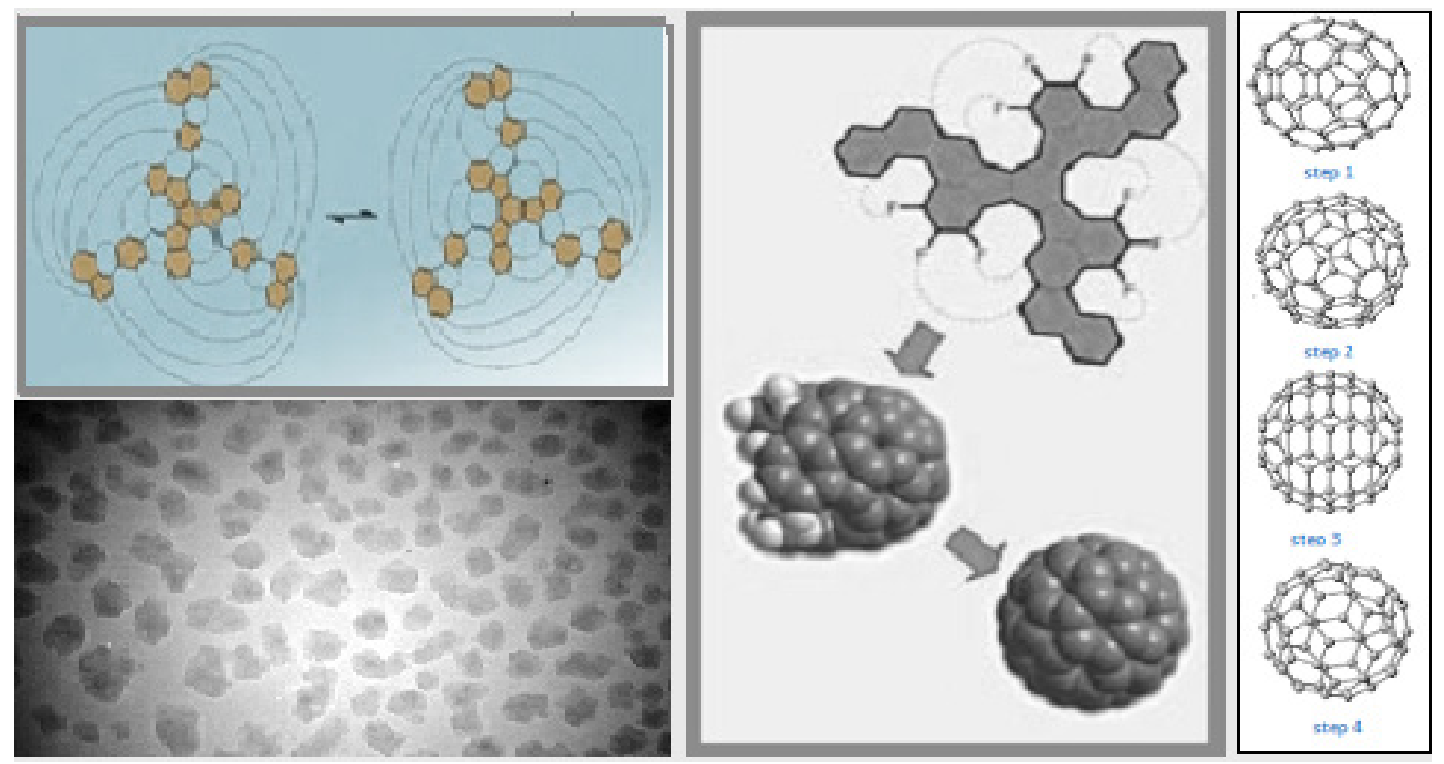

Fig. 1. The schema of light and heavy fullerenes 


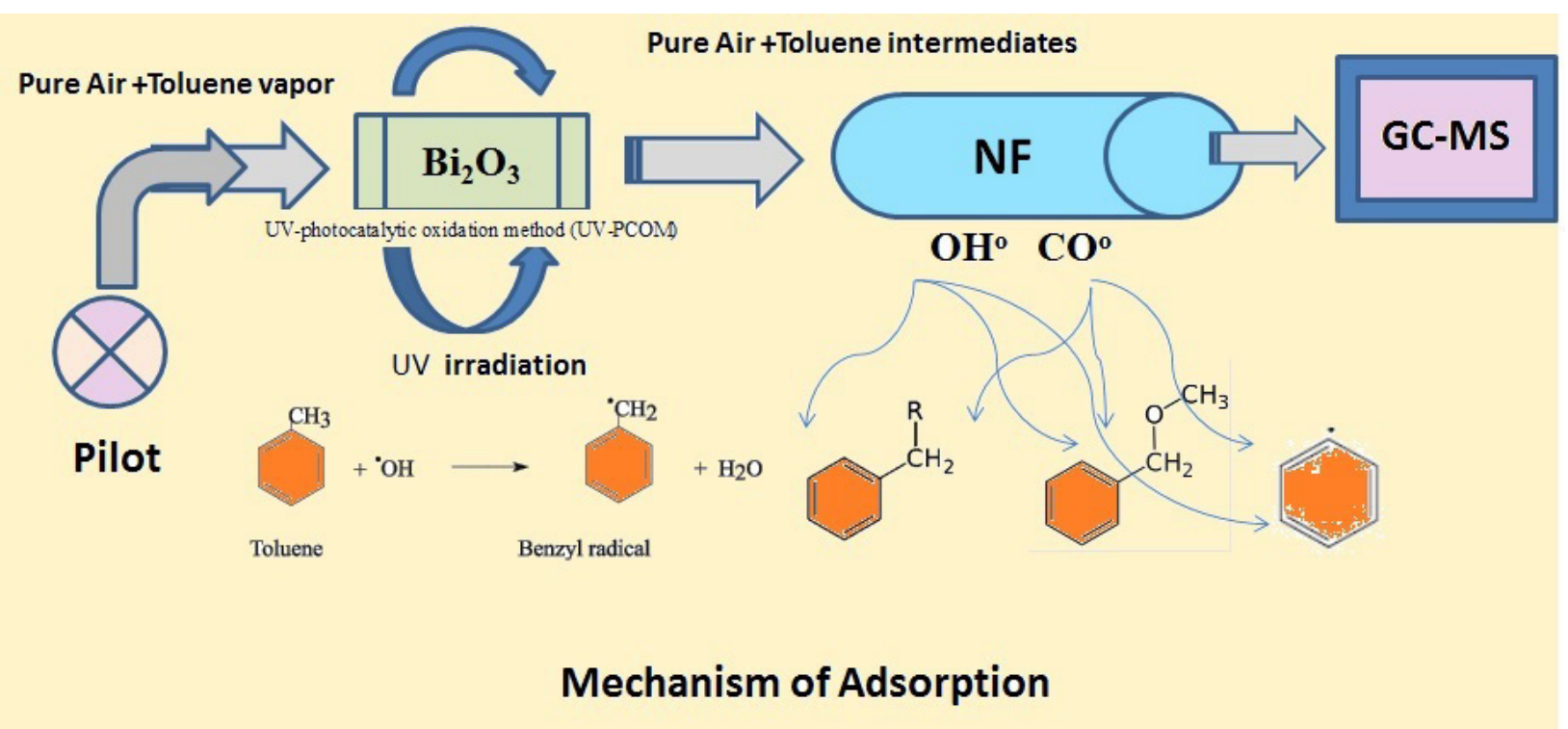

Fig. 2. The pilot of toluene vapor generator in pure air and adsorption procedure

prepared by pilot chamber (Fig. 2). The toluene vapor was generated by and mixed with pure air ( $210 \mathrm{~mL}$ of $\mathrm{O}_{2}$ per L; $2.5 \mathrm{~mL}$ of $\mathrm{H}_{2} \mathrm{O}$ per $\mathrm{L}$ ) at $25^{\circ} \mathrm{C}$. This mixture was restored in polyethylene bag ( 5 Lit) and toluene was determined by GC-MS and GC-FID. Based on producer, in bath scale set up, $10 \mathrm{~mL}$ of standard solutions of toluene $(40-100 \mathrm{mg}$ ) was convert to vapor gas and mixed to pure air and then pass through silica gel and $\mathrm{Bi}_{2} \mathrm{O}_{3}$ nanoparticles with flow rate of $500 \mathrm{~mL} \mathrm{~min}^{-1}$ at $10 \mathrm{~min}$ which was irradiated by UV in quartz glass tube (QGT). Then, toluene and intermediates was absorbed on NF by physically and radically formation. Finally, toluene and intermediates desorbed from $\mathrm{NF}$ at $185^{\circ} \mathrm{C}$ before determined by GC/FID. For validation of methodology, GC-MS and spike of sample was used. This method can be applied for toluene removal from artificial and workplace air.

\section{Results}

In this research, $\mathrm{Bi}_{2} \mathrm{O}_{3}-\mathrm{NF}$ was used for efficient removal of toluene from air. The $\mathrm{Bi}_{2} \mathrm{O}_{3}$ based on $\mathrm{UV}$ irradiation can be increased the removal efficiency of toluene from air by radically adsorption. The characterization of $\mathrm{Bi}_{2} \mathrm{O}_{3} / \mathrm{NF}$ such as TEM, SEM, $\mathrm{XRD}, \mathrm{XRD}$ and IR was prepared. The important parameters include, toluene concentration, intensity of UV irradiation, temperature, the mass of $\mathrm{Bi}_{2} \mathrm{O}_{3}-$ $\mathrm{NF}$, flow rate, time and repeatability were studied and optimized.

\subsection{TEM, SEM, XRD and IR}

The results of synthesis for Bismuth oxide nanoparticles have been obtained in a series of scanning electron microscope (SEM) and transmission electron microscopy (TEM) images. It was clarified that the size of nanoparticles are obtained below $100 \mathrm{~nm}$. The TEM and SEM images of $\mathrm{Bi}_{2} \mathrm{O}_{3}$ have been demonstrated in figure $3(\mathrm{a}, \mathrm{b})$. SEM and TEM of fullerene nanoparticles (NF) was shown in figure $4(a, b)$ which was between 50-100 $\mathrm{nm}$. The XRD of $\mathrm{Bi}_{2} \mathrm{O}_{3}$ and NF was shown in figure $5 \mathrm{a}$ and $5 \mathrm{~b}$, respectively. The IR of NF (C60) was shown in figure 6 .

\subsection{The effects of humidity}

The concentration of toluene vapor in pure air was prepared at $25^{\circ} \mathrm{C}\left(210 \mathrm{~mL}\right.$ of $\mathrm{O}_{2}$ per $\mathrm{L} ; 2.5 \mathrm{~mL}$ of $\mathrm{H}_{2} \mathrm{O}$ per L). This mixture was restored in $5 \mathrm{Li}$ of polyethylene bag. Finally, toluene vapor in pure air was removed from air by UV-PCOM method. By procedure, the effects of humidity on adsorption capacity of $\mathrm{Bi}_{2} \mathrm{O}_{3}-\mathrm{NF}$ in QGT were examined in different humidity (10-60\%). The value of humidity in the pilot chamber was adjusted by the water tank valve by auto electronic system in present of silica gel. By increasing of humidity more than $40 \%$, the removal efficiency of $\mathrm{Bi}_{2} \mathrm{O}_{3}-\mathrm{NF}$ was 


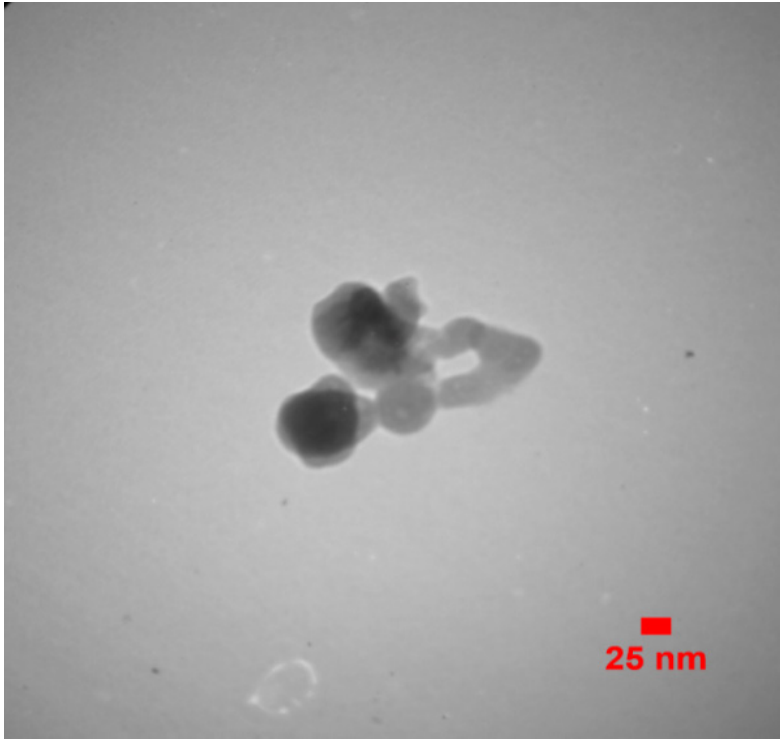

Fig. 3a. TEM picture of $\mathrm{Bi}_{2} \mathrm{O}_{3}$

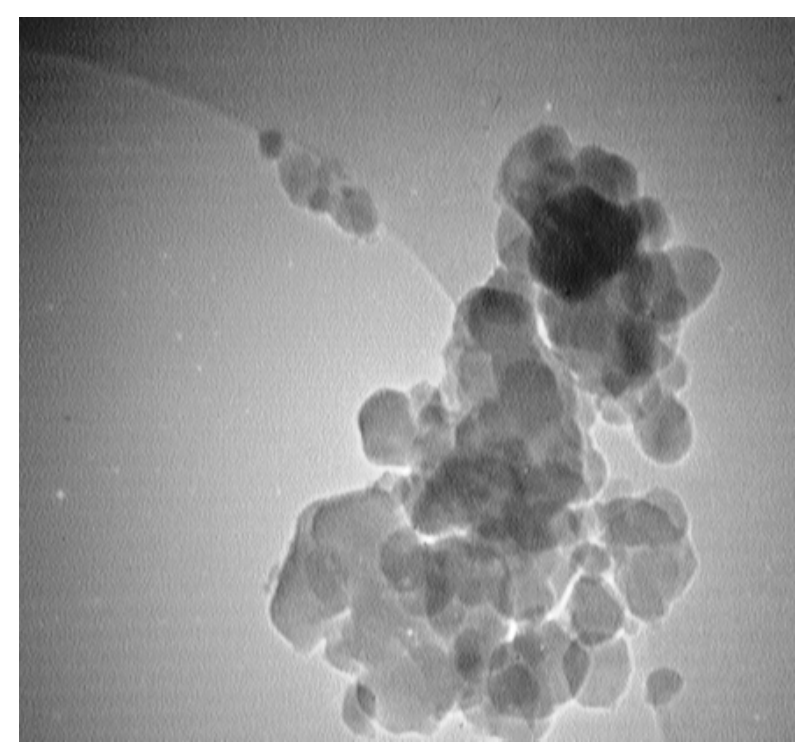

Fig. 4a. TEM picture of NF

decreased (Fig. 7). The Previous study showed that the trap device packed with silica composite multi walled carbon nanotubes (MSN-MWCNTs) prepared based on sol-gel technique was used for evaluation of volatile organic compounds at $20 \%$ humidity. Increasing of humidity may be reduced the adsorption active sites on NF which was occupied by water $(-\mathrm{OH})$. On the other hand, the nanoparticles of NF stick together with water molecules increase in size and decrease of surface

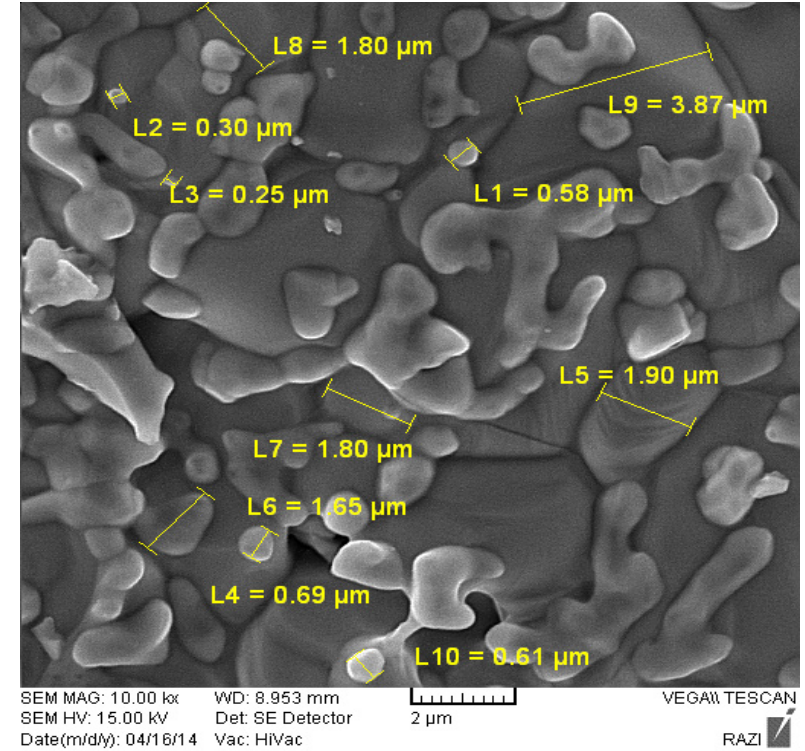

Fig. 3b. SEM picture of $\mathrm{Bi}_{2} \mathrm{O}_{3}$

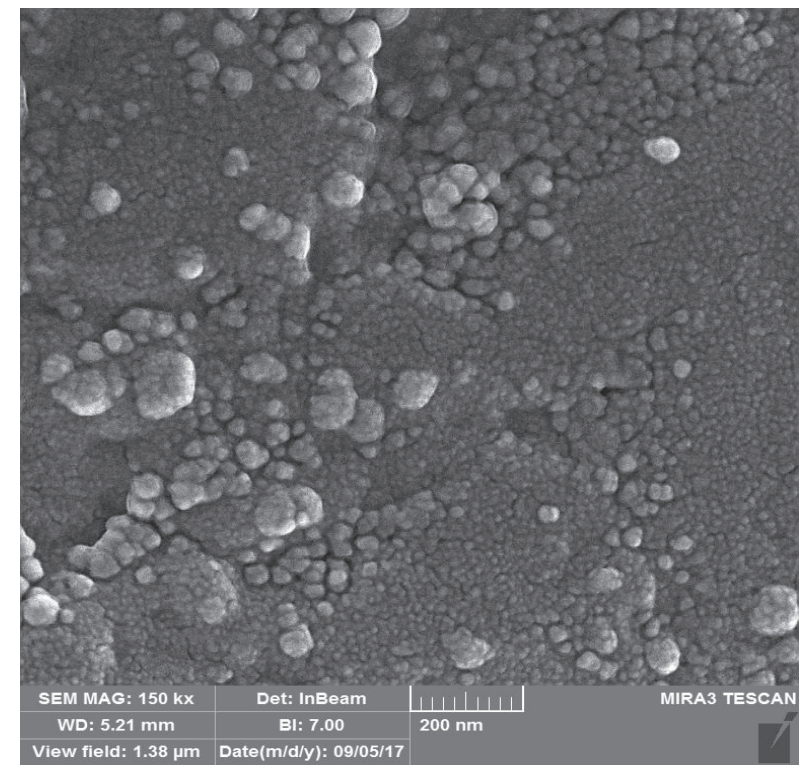

Fig. 4b. SEM picture NF

area. All examinations were achieved by toluene concentration $\left(40 \mathrm{mg} \mathrm{L}^{-1}\right)$, flow rate $\left(500 \mathrm{~mL} \mathrm{~min}^{-}\right.$ $\left.{ }^{1}\right)$, temperature $\left(25^{\circ} \mathrm{C}\right)$, and $200 \mathrm{mg}$ of $\mathrm{Bi}_{2} \mathrm{O}_{3}-\mathrm{NF}$. In optimized condition, the $20 \%$ humidity had low effects on toluene removal from air less than 5\%. Also, the results showed us, the humidity had lower effect than temperature.

\subsection{The effect of toluene concentration}

By optimizing conditions, the toluene removal 


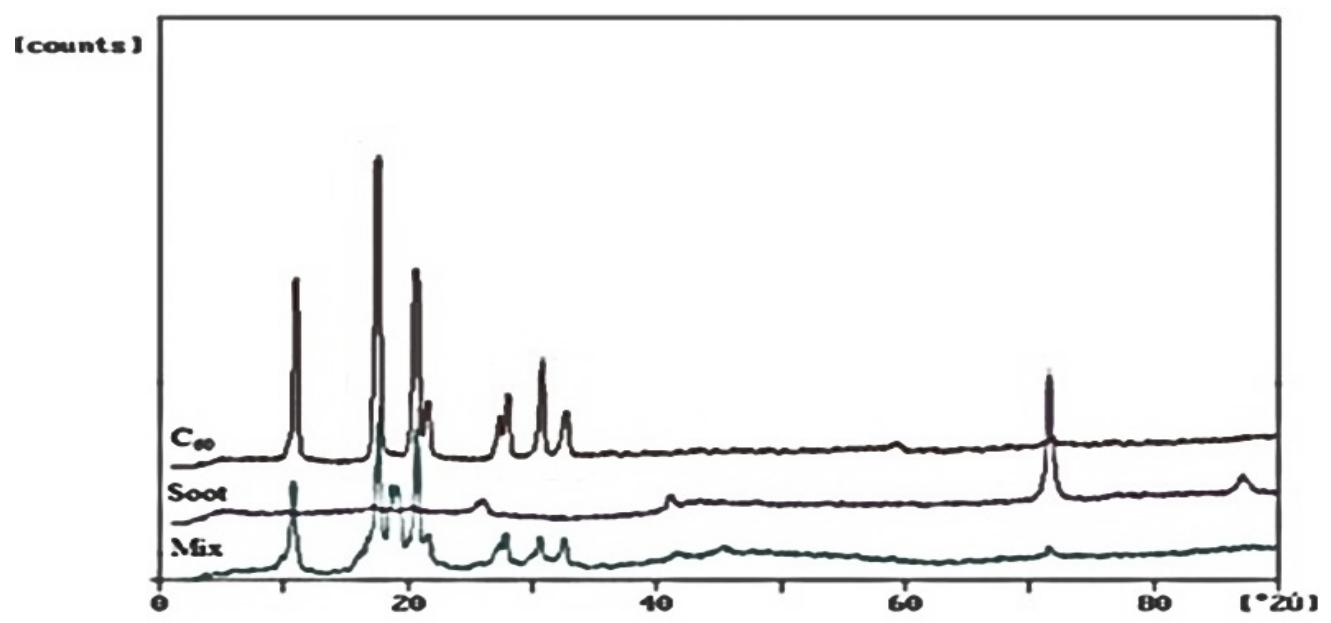

Fig. 5a. XRD spectra of NF

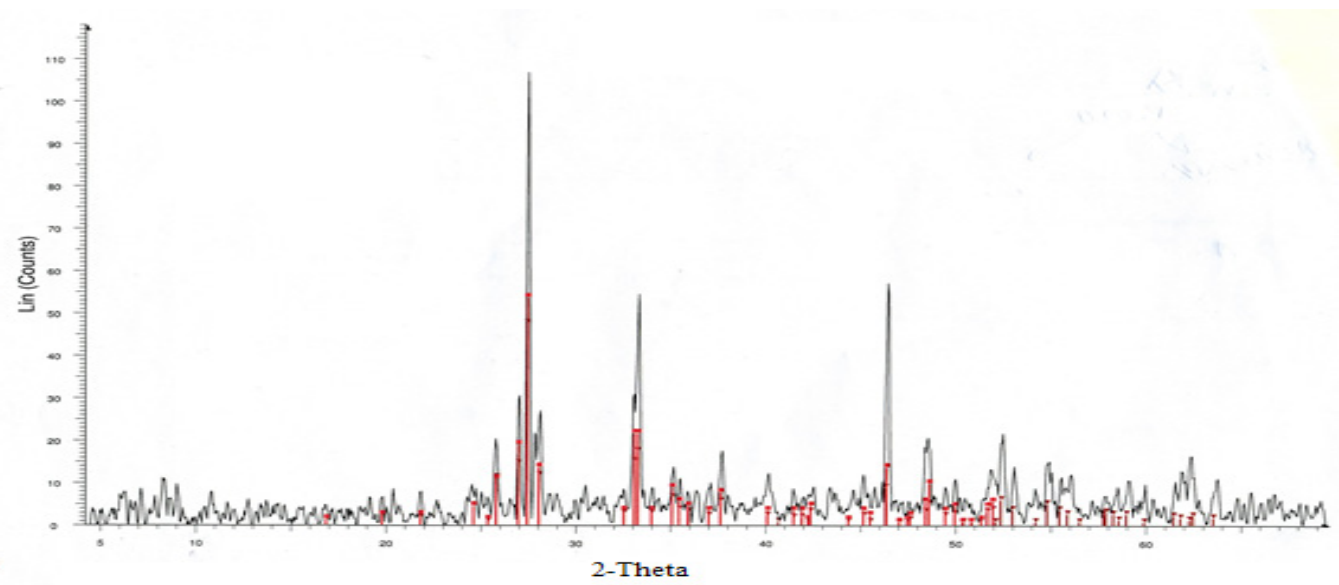

Fig. 5b. XRD spectra of $\mathrm{Bi}_{2} \mathrm{O}_{3}$

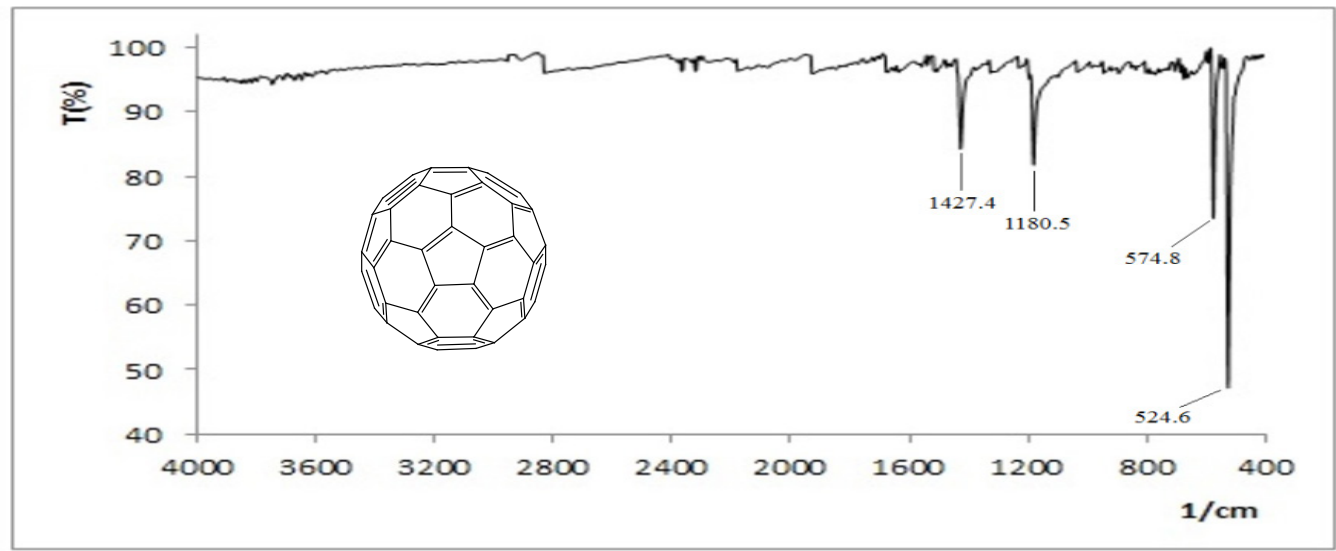

Fig. 6. The IR spectra of NF

from air based on $\mathrm{Bi}_{2} \mathrm{O}_{3}-\mathrm{NF}$ was studied in different toluene concentration from 10-100 ppm ( $\left.\mathrm{mg} \mathrm{L}^{-1}\right)$. The high surface area in NF based on UV lampglass quartz cell accessory (UV-GQC) caused to increasing of the adsorption capacity for toluene removal from air. At high concentration of toluene, the $\mathrm{Bi}_{2} \mathrm{O}_{3}-\mathrm{NF}$ can be acted as a favorite sorbent. The optimum of toluene concentration for removal efficiency (>99\%) with $200 \mathrm{mg}$ of $\mathrm{Bi}_{2} \mathrm{O}_{3}-\mathrm{NF}$, NF, $\mathrm{Bi}_{2} \mathrm{O}_{3}$ was achieved, $42.4 \mathrm{mg} \mathrm{L}^{-1}, 20.6 \mathrm{mg} \mathrm{L}^{-1}$ 


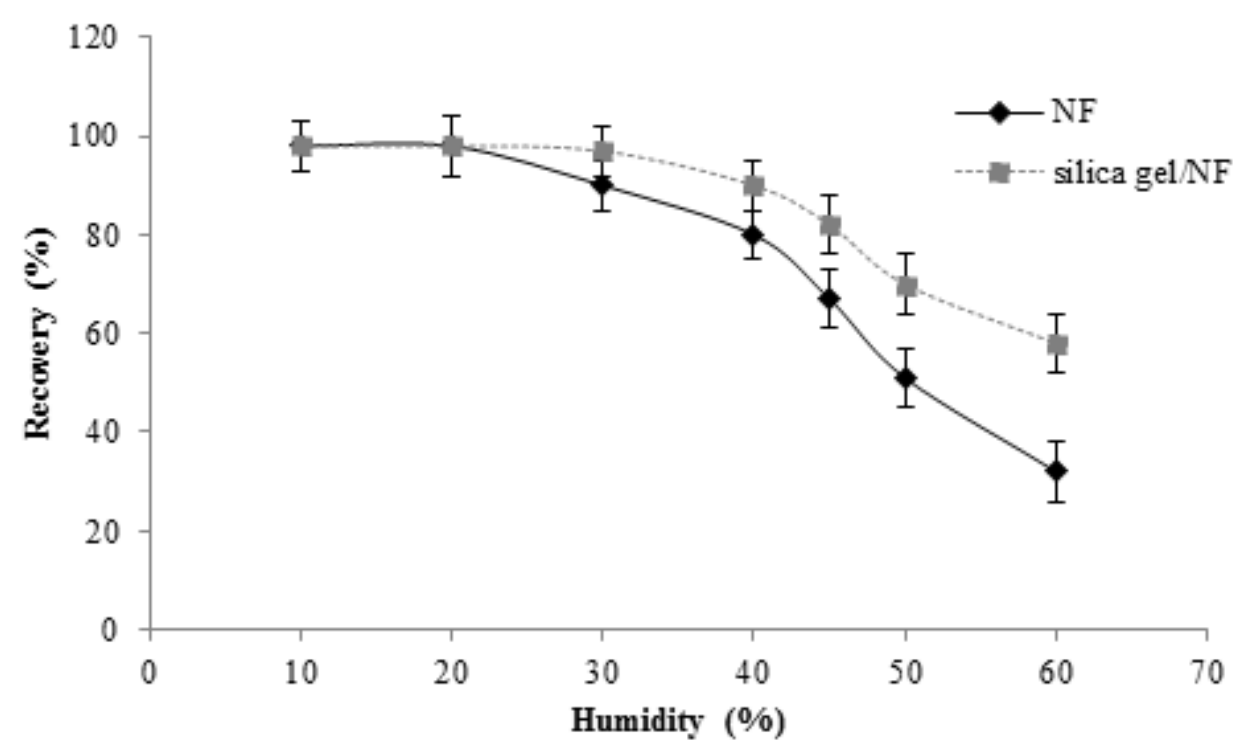

Fig.7. The effects of humidity on toluene adsorption by silica gel/ $\mathrm{Bi}_{2} \mathrm{O}_{3}-\mathrm{NF}$

and $2.3 \mathrm{mg} \mathrm{L}^{-1}$ in $25^{\circ} \mathrm{C}$, respectively. The results showed, in optimized concentration, the $\mathrm{Bi}_{2} \mathrm{O}_{3}$ $\mathrm{NF}$ had more adsorption capacity and removal efficiency than others.

\subsection{The effect of temperature}

The temperature has a main factor for removal efficiency of toluene from air by $\mathrm{Bi}_{2} \mathrm{O}_{3}$-NF. As prevent to condensing toluene, the special thermal accessory was used in pilot chamber for heat controlling up to $115^{\circ} \mathrm{C}$. The column of QGT was used at below $45^{\circ} \mathrm{C}$. The effect of temperature was studied between $20-200^{\circ} \mathrm{C}$. The results showed us, the absorption recovery of $\mathrm{Bi}_{2} \mathrm{O}_{3}-\mathrm{NF}$ was depended to temperature. Desorption of toluene from $\mathrm{Bi}_{2} \mathrm{O}_{3}-$ $\mathrm{NF}$ was occurred at $185^{\circ} \mathrm{C}$. In optimized conditions, the removal recovery for toluene based on $\mathrm{Bi}_{2} \mathrm{O}_{3}-\mathrm{NF}$ was more than NF up to $45^{\circ} \mathrm{C}$ (Fig. 8). Sone et al showed that the adsorption of toluene was decreased by increasing temperature. Increasing temperature more than $50^{\circ} \mathrm{C}$ had negative effects on removal efficiency of $\mathrm{Bi}_{2} \mathrm{O}_{3}-\mathrm{NF}$ and had more effected on humidity. In this study, the adsorption capacity of $\mathrm{Bi}_{2} \mathrm{O}_{3}-\mathrm{NF}$ and NF has obtained $212 \mathrm{mg} \mathrm{g}^{-1}$ and 99.6 $\mathrm{mg} \mathrm{g}^{-1}$, respectively. Other parameters such as, the surface area, flow rate, kind/ porosity/ source/ size sorbent and chemical and physical adsorption can be affected on removal of toluene from air. The low adsorption capacity of nanosorbents related to greater amounts of amorphous structure with low surface area or increasing of temperature.

\subsection{The effect of sorbent mass}

The amounts of $\mathrm{Bi}_{2} \mathrm{O}_{3}-\mathrm{NF}(1: 1)$ as a sorbent in the range of 20 to $300 \mathrm{mg}$ were tested on the recoveries of toluene removal from air at $25^{\circ} \mathrm{C}$. It was found that $220 \mathrm{mg}$ of $\mathrm{Bi}_{2} \mathrm{O}_{3}-\mathrm{NF}$ was sufficient for quantitative recoveries of toluene removal from air. Extra mass of $\mathrm{Bi}_{2} \mathrm{O}_{3}$-NF had no significant effect on the efficient removal of toluene vapor in air. So, $200 \mathrm{mg}$ of $\mathrm{Bi}_{2} \mathrm{O}_{3}-\mathrm{NF}$ was selected as an optimized mass sorbent by UV-PCOM. Also, the $\mathrm{Bi}_{2} \mathrm{O}_{3}$ and $\mathrm{NF}$ and $\mathrm{Bi}_{2} \mathrm{O}_{3}-\mathrm{NF}$ had maximum recovery up to $5.1 \%$ and $48.4 \%$ and more than $95 \%$, respectively. These results confirm that the radically group of $\mathrm{NF}\left(\mathrm{OH}^{\circ}, \mathrm{CO}^{\circ}\right)$ with methyl of toluene $\left(\mathrm{CH}^{\circ}\right)$ had important role for removal of toluene in present of $\mathrm{Bi}_{2} \mathrm{O}_{3}$ by UV-PCOM.

\subsection{The effect of flow rate}

The flow rates were optimized in order to obtain the maximum recovery by proposed method. So, the effect of different flow rates between 100 to $1000 \mathrm{~mL} \mathrm{~min}^{-1}$ was examined by $\mathrm{Bi}_{2} \mathrm{O}_{3}-\mathrm{NF}$ at room temperature. The flow rate was measured by a digital rotameter in input and output of QGT in optimized conditions. The results showed us, the removal efficiency and adsorption capacity of $\mathrm{Bi}_{2} \mathrm{O}_{3}-\mathrm{NF}$ 


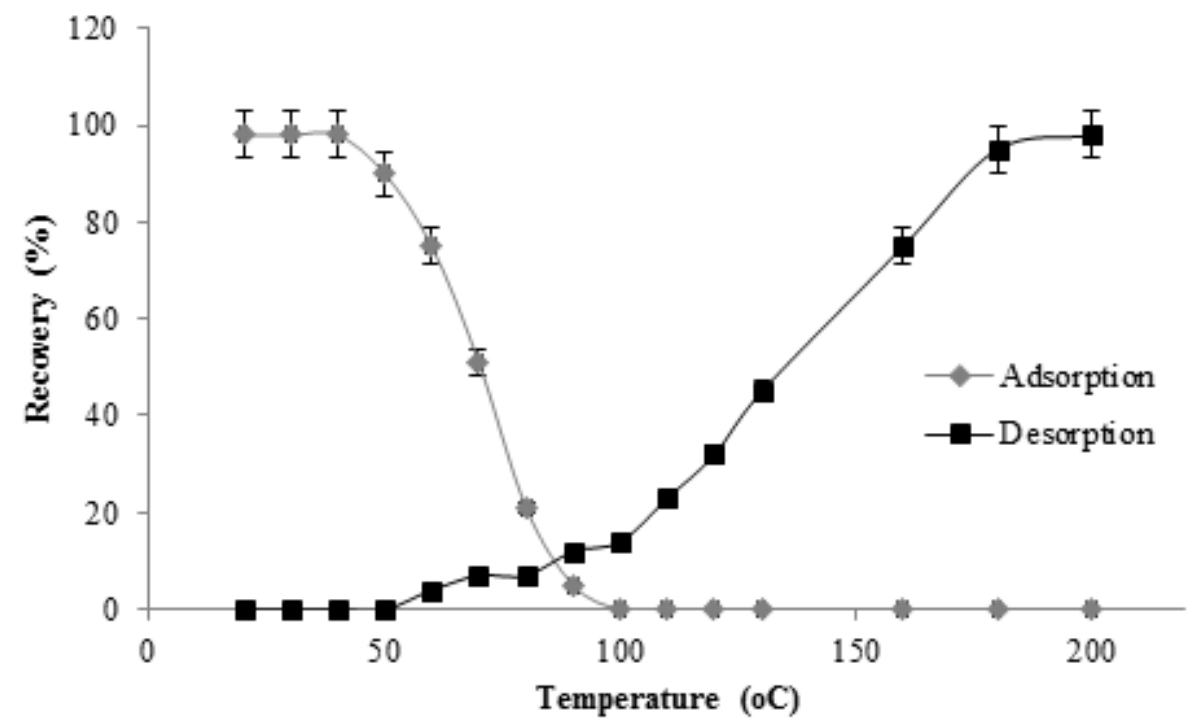

Fig. 8. The effects of temperature on toluene adsorption and desorption from $\mathrm{Bi}_{2} \mathrm{O}_{3}-\mathrm{NF}$

was decreased in more than $550 \mathrm{~mL} \mathrm{~min}^{-1}$ of flow rate. So, $500 \mathrm{~mL} \mathrm{~min}^{-1}$ of flow rate was selected as optimum flow rate for removal of toluene in air. Higher flow rate was significantly decreased the adsorption recovery of $\mathrm{Bi}_{2} \mathrm{O}_{3}-\mathrm{NF}$. Based on results, the maximum of toluene adsorption by exterior and interior sites of NF was obtained at less than 500 $\mathrm{mL} \mathrm{min}^{-1}$. Figure 9 show the effects of difference flow rate on the removal efficiency and adsorption capacity in optimized conditions.

\subsection{Method Validation}

Due to obtained Results, the $\mathrm{Bi}_{2} \mathrm{O}_{3}-\mathrm{NF}$ was selected as a novel sorbent for removal of toluene vapor from air. By proposed method, a mixture of 10-100 ppm of toluene vapor which was generated by pilot, storage in PE bag $(5 \mathrm{~L})$. Then, the mixture of toluene in artificial air moved to $\mathrm{Bi}_{2} \mathrm{O}_{3}-\mathrm{NF}$ in present of argon gas as a carrier gas. The different standard of toluene $(\mathrm{mg})$ in air was validated by high sensitive and accurate GC-FID/GC-MS before using by UV-PCOM. Since no certified reference

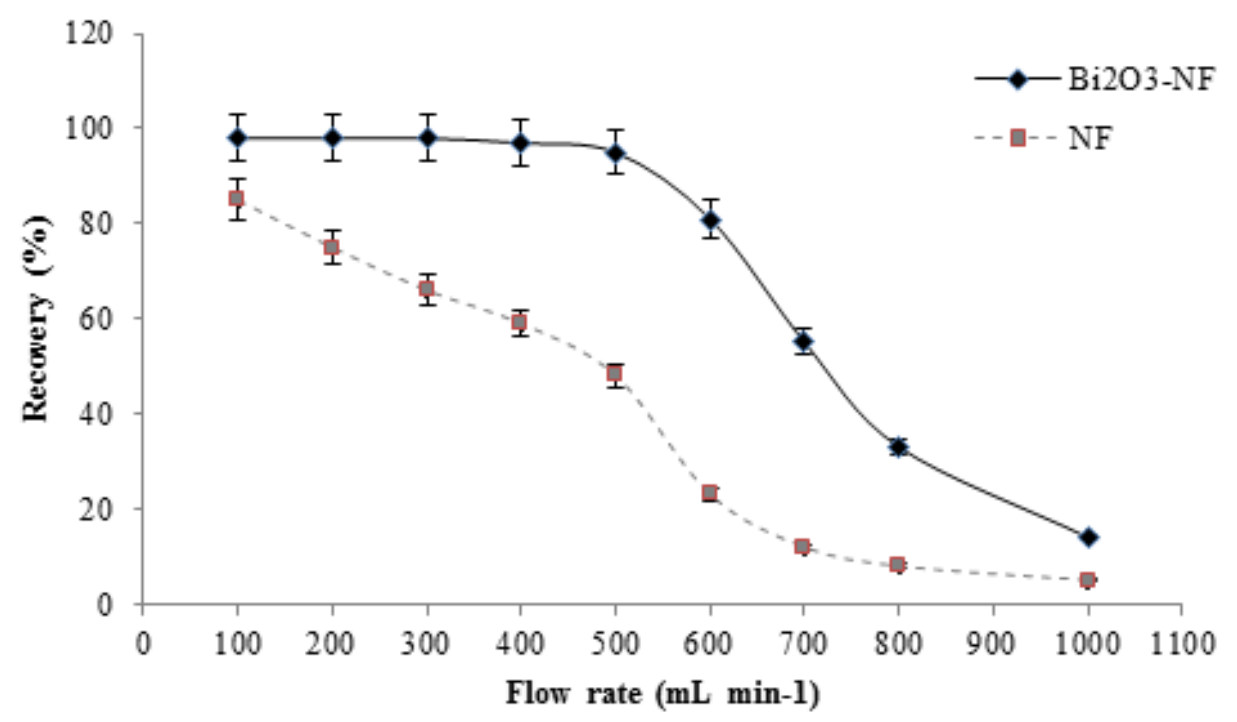

Fig. 9. The effects of flow rate on toluene removal by $\mathrm{Bi}_{2} \mathrm{O}_{3}-\mathrm{NF}$ and $\mathrm{NF}$ 
Table 1. Method validation based on by spike of toluene concentration in artificial air by $\mathrm{Bi}_{2} \mathrm{O}_{3}-\mathrm{NF} / \mathrm{GC}-\mathrm{FID}\left(\mathrm{mg} \mathrm{L}^{-1}\right)$

\begin{tabular}{lllll}
\hline Tolene $^{\mathrm{a}}$ & Bag of pilot & Spike of toluene & Results $^{\mathrm{b}}$ & Recovery $(\%)$ \\
\hline 1.0 & $0.93 \pm 0.04$ & 1.0 & $1 . .79 \pm 0.05$ & 96.2 \\
5.0 & $4.58 \pm 0.27$ & 5.0 & $8.89 \pm 0.46$ & 97.1 \\
10.0 & $9.43 \pm 0.53$ & 5.0 & $14.19 \pm 0.65$ & 101.2 \\
15.0 & $14.39 \pm 0.75$ & 10.0 & $22.54 \pm 1.23$ & 94.6 \\
20.0 & $19.70 \pm 0.96$ & 10.0 & $28.57 \pm 1.33$ & 98.2 \\
25.0 & $24.65 \pm 1.14$ & 15.0 & $40.11 \pm 2.16$ & 102.7 \\
\hline
\end{tabular}

a (Floe rate $500 \mathrm{~mL} \mathrm{~min}^{-1}$, Peak Area of GC-FID, $200 \mathrm{mg}, \mathrm{T}=45^{\circ} \mathrm{C}$ )

${ }^{\mathrm{b}}$ (Mean of three determinations \pm confidence interval, $\mathrm{P}=0.95 ; \mathrm{n}=5$ )

material (CRM) for toluene in air are currently available, the spiked of toluene concentration (10$100 \mathrm{ppm}$ ) were used for validation of proposed method. At optimized conditions in 5 and 10 minute, $20 \mathrm{ppm}$ and $40 \mathrm{ppm}$ of toluene vapor in air was almost removed by $\mathrm{Bi}_{2} \mathrm{O}_{3}-\mathrm{NF}$, respectively (bag $5 \mathrm{~L}$ ). The efficient recovery of spiked samples is satisfactorily reasonable which indicates the power ability of UV-PCOM based on $\mathrm{Bi}_{2} \mathrm{O}_{3}$-NF for removal of air toluene. After thermal desorption of $\mathrm{Bi}_{2} \mathrm{O}_{3}-\mathrm{NF}$ in QGT, the toluene concentration was on-line determined by GC-FID. The validation of methodology was confirmed using GC-MS (Table $1,2)$.

\section{Discussion}

Volatile organic compounds (VOCs) are released from various sources such as chemical processing industries involved with the manufacturing, handling, and the distribution of paints, lubricants, and liquid fuels and are unsafe for human health are known to have and environmental functions[37]. The numerous VOC treatment technologies have emerged, such as incineration, condensation, biological degradation, absorption, adsorption, and catalysis oxidation. One of the common techniques to monitor BTX in ambient air is the use of a sorbent/solvent for the trapping and extracting of VOCs from air or gas[38]. In this study, the toluene removal from air was investigated based on mixture of bismuth oxide-fullerene nanoparticles $\left(\mathrm{Bi}_{2} \mathrm{O}_{3}\right.$ NF) by UV-photocatalytic oxidation method (UVPCOM). The obtained results showed that flow rate and temperature had highly impact on NF for removal efficiency and absorption capacity of toluene from air. Many researchers investigated on toluene removal from air based on various absorbents. The removal of toluene from air through Nano-graphene modified by ionic liquid (NG-IL) was studied. In this study the effect of different conditions such as; toluene concentration, humidity, and temperature on the adsorption were investigated. The results showed the adsorption

Table 2. Comparing of $\mathrm{Bi}_{2} \mathrm{O}_{3}-\mathrm{NF}, \mathrm{Bi}_{2} \mathrm{O}_{3}$ and NF for removal of toluene from artificial air by GC-FID/GC-MS (mg L-1)

\begin{tabular}{ccccccc}
\hline Sorbent $^{*}$ & Bag & Added & GC-FID $^{\text {a }}$ & GC-MS & GC-FIDRecovery (\%) & GC-MS Recovery (\%) \\
\hline NF & 5.0 & ----- & $2.34 \pm 0.02$ & $2.45 \pm 0.02$ & 46.8 & 49.0 \\
& & 5.0 & $4.53 \pm 0.03$ & $4.78 \pm 0.04$ & 43.8 & 46.6 \\
Bi2O3-NF & 5.0 & ----- & $4.88 \pm 0.05$ & $4.93 \pm 0.06$ & 43.4 & 46.4 \\
& & 5.0 & $9.71 \pm 0.09$ & $9.77 \pm 0.10$ & 96.6 & 98.6 \\
Bi2O3 & \multirow{2}{*}{5.0} & 10.0 & $14.95 \pm 0.15$ & $14.64 \pm 0.16$ & 101.1 & 96.7 \\
& & 5.0 & $1.43 \pm 0.07$ & $1.51 \pm 0.05$ & 1.5 & 97.1 \\
& & 10.0 & $2.24 \pm 0.12$ & $2.33 \pm 0.09$ & 1.4 & 1.5 \\
\hline
\end{tabular}

a (Mean of three determinations \pm confidence interval, $\mathrm{P}=0.95 ; \mathrm{n}=5$ )

* (500 $\mathrm{mL} \mathrm{min}^{-1}$ air flow rate, $\left.200 \mathrm{mg}, \mathrm{T}=45^{\circ} \mathrm{C}\right)$ 
capacity was decreased by raising the sorbent humidity above 50 percent and the toluene capture capacity for NG-IL was $126 \mathrm{mg} \mathrm{g}^{-1}$ which was lower than $\mathrm{Bi}_{2} \mathrm{O}_{3}-\mathrm{NF}$ [27]. By UV-photocatalytic oxidation method, the capacity of toluene absorption with $\mathrm{Bi}_{2} \mathrm{O}_{3}-\mathrm{NF}$ was $212 \mathrm{mg} \mathrm{g}^{-1}$ which was depended to UV-photocatalytic oxidation. Lillo-Ródenas showed that the removal percentage for toluene also may depend on porosity and the surface chemistry of adsorbent. They showed that adsorption capacities for benzene and toluene was obtained $34 \mathrm{~g}$ per $100 \mathrm{~g}$ activated carbon(AC) and $64 \mathrm{~g}$ per $100 \mathrm{~g}$, respectively which is lower than $\mathrm{Bi}_{2} \mathrm{O}_{3}-\mathrm{NF}$ by UV-PCOM [39]. Surface chemistry of activated carbon has an important role on the removal of aromatic compounds in air because it affects both electrostatic and dispersive interactions between adsorbents and adsorbates [40]. In proposed method, the chemically absorption of toluene on NF mainly obtain due to radically group of $\mathrm{NF}(\mathrm{OHo}, \mathrm{COo})$ with methyl of toluene $(\mathrm{CH} 2 \mathrm{o})$. Rezaei et al. have been used as complex system of nano-particles of titanium dioxide on exposing them by ultraviolet radiation. The results showed titanium dioxide nanoparticles when subjected to ultraviolet radiation, exhibit strong oxidizing and regenerative properties and can be used to remove toluene vapors in high concentrations but it need more time for adsorption process and titanium dioxide nanoparticles is expensive as compare to carbon compounds [41]. In addition, the use of a suitable adsorbent according to the type of sorption can be helped for removal toluene from air. Ichiura at el. has suggested a sorbent based on zeolite or activated carbon as a photocatalyst bed to improve the efficiency of adsorption with higher recovery [42].

Shojaee showed that ZSM-5 has a porous surface with surface area of $356.4 \mathrm{~m}^{2}$ per gram. That after the calcination at temperature of $450^{\circ} \mathrm{c}$ it decreased to $332.5 \mathrm{~m}^{2}$ per gram. The results of the photocatalytic degradation process showed that the best performance of $\mathrm{ZSM}-5 / \mathrm{TiO}_{2}$ bed was at concentration of $0 \cdot \mathrm{ppm}$, so that was able to remove $\%$ \& r toluene vapors which was lower than
$\mathrm{Bi}_{2} \mathrm{O}_{3}-\mathrm{NF}[43,44]$. According to obtained results, removal of toluene from air based on $\mathrm{Bi}_{2} \mathrm{O}_{3}-\mathrm{NF} /$ UV-PCOM was very rapid and absorption capacity increased up to $212 \mathrm{mg}$ per gram. Rezaee et al. studied on the potential of $\mathrm{MnO} / \mathrm{GAC}$ and $\mathrm{MgO} /$ GAC composites for toluene adsorption from air stream. They showed that, by increasing inlet toluene concentration from 100 to $400 \mathrm{ppm}$, the breakthrough time of $\mathrm{MgO} / \mathrm{GAC}$ and $\mathrm{MnO} / \mathrm{GAC}$ was decreased [45]. So, the proposed method based on $\mathrm{Bi}_{2} \mathrm{O}_{3}-\mathrm{NF}$ had many advantages such as, high efficiency, simple, low cost for toluene removal from air as compared to other methods.

\section{Conclusions}

In this study, the removal of toluene from air was obtained based on $\mathrm{Bi}_{2} \mathrm{O}_{3}-\mathrm{NF}$ and UV-PCOM. By procedure, many advantages such as, high efficiency, high capacity, low cost, simple and fast adsorption was achieved. In optimized conditions, toluene concentration, $\mathrm{Bi}_{2} \mathrm{O}_{3}-\mathrm{NF}$ mass, temperature and flow rate were evaluated. The capacity of sorbents, recovery, and removal efficiency of $\mathrm{Bi}_{2} \mathrm{O}_{3}-\mathrm{NF}, \mathrm{Bi}_{2} \mathrm{O}_{3}$ and NF was studied by CG-FID and GC-MS. Based on the results, the recovery of $\mathrm{Bi}_{2} \mathrm{O}_{3}-\mathrm{NF}$ was more than $\mathrm{Bi}_{2} \mathrm{O}_{3}$ and NF sorbents. Also, the maximum adsorption of toluene was achieved with $200 \mathrm{mg}$ of $\mathrm{Bi}_{2} \mathrm{O}_{3}$-NF by flow rate of $500 \mathrm{~mL} \mathrm{~min}^{-1}\left(45^{\circ} \mathrm{C}\right)$. Thermal accessory was used for toluene desorption from $\mathrm{Bi}_{2} \mathrm{O}_{3}-\mathrm{NF}$ at 180 ${ }^{\circ} \mathrm{C}$. Due to characteristics of $\mathrm{Bi}_{2} \mathrm{O}_{3}-\mathrm{NF}$ based on physically and radically adsorption, toluene was efficient removed from air by proposed method.

\section{References}

[1] W. T. Tsai, Toxic volatile organic compounds (VOCs) in the atmospheric environment: Regulatory aspects and monitoring in Japan and Korea, Environ., 3 (2016) 23.

[2] M.A. Bari, W.B. Kindzierski, Ambient volatile organic compounds (VOCs) in communities of the Athabasca oil sands region: Sources and screening health risk assessment, Environ. Pollut., 235 (2018) 602-614 
[3] B.C. McDonald, J.A. de Gouw, J.B. Gilman, S.H. Jathar, A. Akherati, C.D. Cappa, J.L. Jimenez, J. Lee-Taylor, P.L. Hayes, S.A. McKeen, Volatile chemical products emerging as largest petrochemical source of urban organic emissions, Sci., 359 (2018) 760-764.

[4] Z. Cheng, B. Li, W. Yu, H. Wang, T. Zhang, J. Xiong, $\mathrm{Z}$. Bu, Risk assessment of inhalation exposure to VOCs in dwellings in Chongqing, China, Toxicol. Res., 7 (2018) 59-72.

[5] L. Zhong, F.-C. Su, S. Batterman, Volatile organic compounds (VOCs) in conventional and high performance school buildings in the US, Int. J. Environ. Res. Public Health, 14 (2017) 100.

[6] J.C. Lerner, E. Sanchez, J. Sambeth, A. Porta, Characterization and health risk assessment of VOCs in occupational environments in Buenos Aires, Argentina, Atmospheric. Environ., 55 (2012) 440-447.

[7] I.A.f.R.o. Cancer, IARC monographs on the evaluation of carcinogenic risks to humans, agents classified by the IARC monographs, (2015). Retrieved from http7/monographs. Iarc, fr/eng/ classification/index. Php.

[8] A.J. Wheeler, S.L. Wong, C. Khoury, J. Zhu, Predictors of indoor BTEX concentrations in Canadian residences, Health Rep., 24 (2013) 11.

[9] S.J. Lawrence, Description, properties, and degradation of selected volatile organic compounds detected in ground water, a review of selected literature, 2006.

[10] X. Xu, P. Wang, W. Xu, J. Wu, L. Chen, M. Fu, D. Ye, Plasma-catalysis of metal loaded SBA-15 for toluene removal: comparison of continuously introduced and adsorption-discharge plasma system, Chem. Eng. J., 283 (2016) 276-284.

[11] W.K. Boyes, M. Bercegeay, L. Degn, T.E. Beasley, P.A. Evansky, J.C. Mwanza, A.M. Geller, C. Pinckney, T.M. Nork, P.J. Bushnell, Toluene inhalation exposure for 13 weeks causes persistent changes in electroretinograms of Long-Evans rats, Neurotoxicol., 53 (2016) 257-270.

[12] Y. Li, J. Miao, X. Sun, J. Xiao, Y. Li, H. Wang,
Q. Xia, Z. Li, Mechanochemical synthesis of $\mathrm{Cu}-$ BTC@ GO with enhanced water stability and toluene adsorption capacity, Chem. Eng. J, 298 (2016) 191-197.

[13] C.Y.H. Chao, C. Kwong, K. Hui, Potential use of a combined ozone and zeolite system for gaseous toluene elimination, J. Hazard. Mater., 143 (2007) 118-127.

[14] M. Salar-García, V. Ortiz-Martínez, F. HernándezFernández, A. de Los Ríos, J. Quesada-Medina, Ionic liquid technology to recover volatile organic compounds (VOCs), J. Hazard. Mater., 321 (2017) 484-499.

[15] D. Romero, D. Chlala, M. Labaki, S. Royer, J.P. Bellat, I. Bezverkhyy, J.-M. Giraudon, J.-F. Lamonier, Removal of toluene over $\mathrm{NaX}$ zeolite exchanged with $\mathrm{Cu} 2+$, Catalysts, 5 (2015) 14791497.

[16] Y.J. Tham, P.A. Latif, A.M. Abdullah, A. ShamalaDevi, Y. Taufiq-Yap, Performances of toluene removal by activated carbon derived from durian shell, Bioresour. Technol., 102 (2011) 724-728.

[17] NIOSH manual of analytical methods, NIOSH, (1987).

[18] H. Sui, H. Liu, P. An, L. He, X. Li, S. Cong, Application of silica gel in removing high concentrations toluene vapor by adsorption and desorption process, J. Taiwan Ins. Chem. Eng., (2017).

[19] Z. Sihaib, F. Puleo, J. Garcia-Vargas, L. Retailleau, C. Descorme, L. Liotta, J. Valverde, S. Gil, A. Giroir-Fendler, Manganese oxide-based catalysts for toluene oxidation, App. Cat. B Environ., 209 (2017) 689-700.

[20] Z. Pengyi, L. Fuyan, Y. Gang, C. Qing, Z. Wanpeng, A comparative study on decomposition of gaseous toluene by O3/UV, TiO2/UV and O3/TiO2/UV, J. Photochem. Photobiol., 156 (2003) 189-194.

[21] S. Wang, H. Sun, H.-M. Ang, M. Tadé, Adsorptive remediation of environmental pollutants using novel graphene-based nanomaterials, Chem. Eng. J., 226 (2013) 336-347.

[22] G.B. Baur, O. Beswick, J. Spring, I. Yuranov, L. 
Kiwi-Minsker, Activated carbon fibers for efficient VOC removal from diluted streams: the role of surface functionalities, Adsorption, 21 (2015) 255264.

[23] A. Faghihi-Zrandi, M. Akhgar, Volatile Organic Compounds (VOCs) in the Ambient Air Of Concentration Unit of Sar-Cheshmeh Copper Complex, Environ. Sci. Technol., 18 (2016) 23-31.

[24] G. Quijano, A. Couvert, A. Amrane, G. Darracq, C. Couriol, P. Le Cloirec, L. Paquin, D. Carrié, Potential of ionic liquids for VOC absorption and biodegradation in multiphase systems, Chem. Eng. Sci., 66 (2011) 2707-2712.

[25] F.G. Shahna, F. Golbabaei, J. Hamedi, H. Mahjub, H.R. Darabi, S.J. Shahtaheri, Treatment of benzene, toluene and xylene contaminated air in a bioactive foam emulsion reactor, Chinese.Chem. Eng., 18 (2010) 113-121.

[26] F. Su, C. Lu, S. Hu, Adsorption of benzene, toluene, ethylbenzene and p-xylene by $\mathrm{NaOCl}$-oxidized carbon nanotubes, Colloids Surface A, 353 (2010) 83-91.

[27] H. Shirkhanloo et al, Nobel Method for Toluene Removal from Air Based on Ionic Liquid Modified Nano-Graphen, Iranian J. Occp. Health, 6 (2015) $1-5$.

[28] M.R. Wiesner, G.V. Lowry, P. Alvarez, D. Dionysiou, P. Biswas, Assessing the risks of manufactured nanomaterials, Environ. Sci. Technol., 40 ( 2006) 4336-4345.

[29] Y. Li, Y. Wang, K.D. Pennell, L.M. Abriola, Investigation of the transport and deposition of fullerene (C60) nanoparticles in quartz sands under varying flow conditions, Environ. Sci. Technol., 42 (2008) 7174-7180.

[30] A.G.C. A.V. Rode, E.G. Gamaly, S.T. Hyde, B. Luther Davie, carbon based magnetism, an overview of the magnetism of metal free carbonbased compounds and materials, Elsevier, (2006) 463-482.

[31] T. Oppenländer, Photochemical purification of water and air: advanced oxidation processes (AOPs)-principles, reaction mechanisms, reactor concepts, John Wiley \& Sons, (2003).

[32] G.Y.M. Al-Nour, Photocatalytic degradation of organic contaminants in the presence of graphite supported and unsupported $\mathrm{ZnO}$ modified with $\mathrm{CdS}$ particles, Nablus: An-Najah National University, (2009).

[33] H.I. De Lasa, B. Serrano, M. Salaices, Photocatalytic reaction engineering, Springer, 2005.

[34] C. Montalvo-Romero, C. Aguilar-Ucán, M. Ramirez-Elias, V. Cordova-Quiroz, A Semi-Pilot Photocatalytic Rotating Reactor (RFR) with Supported TiO2/Ag Catalysts for Water Treatment, Molecul., 23 (2018) 224.

[35] U.L. Rochetto, E. Tomaz, Degradation of volatile organic compounds in the gas phase by heterogeneous photocatalysis with titanium dioxide/ultraviolet light, J. Air Waste Manag. Assoc, 65 (2015) 810-817.

[36] H. Keypour, M. Noroozi, A. Rashidi, An improved method for the purification of fullerene from fullerene soot with activated carbon, celite, and silica gel stationary phases, J. Nanostruct. Chem., 3 (2013) 45.

[37] K. Patil, S. Jeong, H. Lim, H.-S. Byun, S. Han, Removal of volatile organic compounds from air using activated carbon impregnated cellulose acetate electrospun mats, Environ. Eng. Res., (2018).

[38] X. Zhang, B. Gao, A.E. Creamer, C. Cao, Y. Li, Adsorption of VOCs onto engineered carbon materials: A review, J. Hazard. Mater., 338 (2017) 102-123.

[39] M. Lillo-Ródenas, D. Cazorla-Amorós, A. LinaresSolano, Behaviour of activated carbons with different pore size distributions and surface oxygen groups for benzene and toluene adsorption at low concentrations, Carbon, 43 (2005) 1758-1767.

[40] F. Villacañas, M.F.R. Pereira, J.J. Órfão, J.L. Figueiredo, Adsorption of simple aromatic compounds on activated carbons, J. Colloid. Interface. Sci, 293 (2006) 128-136.

[41] H. Ichiura, T. Kitaoka, H. Tanaka, Removal of indoor pollutants under UV irradiation by a composite 
TiO2-zeolite sheet prepared using a papermaking technique, Chemosphere, 50 (2003) 79-83.

[42] Rezaee A., Pourtaghi Gh. H., Khavanin A., Saraf Mamoori R., Hajizadeh E., Vali pour F., Elimination of toluene by Application of ultraviolet irradiation on TiO2 nano particles photocatalyst, Mil. Med., 9 (2007) 217-222.

[43] H. Asilian Mahabady, A. Khavanin, M. Nakhaei pour, H. irvani, S. Aresoomandan, H. Shojaee fareh abady, Efficiency evaluation of the photocatalytic removal of toluene vapour by titanium dioxide nanoparticles immobilized on ZSM-5 zeolite, Iran Occp. Health J., 15 (2018) 17-25.

[44] R. Jonidi Jafar, Survey of Modified Clinoptilolite Zeolite and Cooper Oxide NanoparticlesContaining Modified Clinoptilolite Efficiency for Polluted Air BTX Removal, Iranian J. Health Environ., 5 (2012).

[45] F. Rezaei, G. Moussavi, A.R. Riyahi Bakhtiari, Y. Yamini, Toluene adsorption from waste air stream using activated carbon impregnated with manganese and magnesium metal oxides, Iranian J. Health Environ., 8 (2016) 491-508. 